\title{
nature
}

13 May 2004 Volume 429 Issue no 6988

\section{Think harder about ecstasy}

Advocates of therapeutic uses of the drug ecstasy have won the right to research its performance, but opponents continue to snipe. Both sides need to look more deeply into their research agendas.

$\mathrm{n}$ a series of studies beginning this year, doctors will give patients with mental problems a drug to try to ease their trauma. But unlike most other drugs tested in clinical trials today, this experimental treatment, MDMA, or ecstasy, is also widely used in clubs around the world. Proponents of the MDMA trials say that they are long overdue, and have been stalled by political concerns (see page 126). Opponents of the trials say that the trials' organizers are playing with fire by introducing potentially toxic substances into perhaps unstable people. So who is right?

The truth is that there is a shortage of scientific logic on both sides of the MDMA debate. Those who demonize the drug are so convinced of its deadly nature that, when Johns Hopkins researcher George Ricaurte reported that even a single dose of MDMA causes debilitating, Parkinson's-like disease in monkeys (G. Ricaurte et al. Science 297, 2260-2263; 2002), the paper was widely touted as proof that MDMA was fatally toxic. Nobody had reported similar findings before, but this mattered little; anti-drug activists had the proof they had long been seeking that MDMA was much worse than just a harmless party drug.

But it later emerged that the findings were fatally flawed because the MDMA had been mixed up with methamphetamine - a drug of abuse already known to be potentially fatal. The available evidence shows that MDMA can cause psychosis, hyperthermia and even death in some people who take the drug recreationally. But there is no research to indicate whether or not this will be a problem in the controlled settings of a clinical trial, or whether such controlled administration might result in long-term brain damage.
On the other side of the debate, MDMA's supporters claim that the drug is a potentially valuable therapeutic aid with little risk of causing lasting brain damage. They argue that studies showing that MDMA leads to cognitive deficiencies are procedurally flawed, and that there is no proof that a few doses of the drug will cause harm. They point to anecdotal reports of the drug's benefits to show that it should be evaluated as a possible aid to psychotherapy for debilitating conditions such as post-traumatic stress disorder. But no rigorously controlled trials have suggested that MDMA has longterm curative properties, and the drug's effects on people with serious mental disturbances have not been evaluated. The drug has also been reported in conjunction with at least 12 cases of psychosis in the medical literature.

Of course, much scientific research is driven by non-scientific motivations, and no drug would ever be proven to work in clinical trials without an interested champion. But in this case, both sides in the debate would benefit by taking a step back and re-focusing their work.

MDMA's detractors in particular would be wise to study the more immediate and realistic side effects of the drug, such as its interactions with other drugs of abuse, and the processes whereby it can sometimes lead to life-threatening hyperthermia. This more reflective approach would help researchers learn more about the origins of and responses to the frightening side effects that sometimes occur when users take MDMA as a recreational drug. This would surely be a better way of ensuring that safe treatments reach the patients who need them.

\section{South Africa's new voice}

The recent appointment of research minister Mosibudi Mangena bodes well for science, provided that people listen to him.

A fter a decade of democratic government in South Africa, the face of research remains largely untransformed. Published research has declined significantly in relation to global output, and spending on research and development (R\&D) has declined as a proportion of gross domestic product (GDP). White scientists still produce more than $90 \%$ of research articles published. Moreover, the research community is ageing, with almost half of authors of research articles now being over 50. Very few able school-leavers are being attracted into research careers and, despite the de-segregation of the country's school system, only a tiny proportion of black scholars leave school with universityentrance qualifications in mathematics and physical science. Those who do are attracted to careers in the professions, which are perceived as more lucrative.

But a glimmer of hope lies in President Thabo Mbeki's choice of minister of science and technology, Mosibudi Mangena, in his new coalition government (see page 117). Mangena has a background as an applied mathematician and has the experience of having served for the past three years as deputy minister of education. In this capacity he has gained an insight, in particular, into the underlying problem that faces South African science - a lack of qualified teachers and resources to educate its huge school-going population.

Initial indications are that Mangena will not hesitate to articulate solutions, but these will require financing, in the face of many other pressing demands. In his first official appearance as minister last week — launching National Science Week — Mangena made it clear that he regards reform of the science education system as a priority. He has been no less forthright in advocating increased state spending on $R \& D$. The question is whether this will cut any ice with government, particularly as, like his predecessor, he represents a minority party. But the South African cabinet would do well to give him a good hearing.

There are also signs that the government's approach to AIDS is becoming more pragmatic, at least in its election promises. By being equally forthright in this sphere, Mangena could contribute to healing the rift between government and scientists that emerged four years ago following Mbeki's rejection of the prevailing understanding of the disease. Regrettably, Mbeki has not replaced his health minister, Manto Tshabalala-Msimang, whose tardiness in executing changes in anti-retroviral policy remains an obstacle to progress. 